\title{
An improved ITU-R rain attenuation prediction model over terrestrial microwave links in tropical region
}

\author{
Rafiqul MD Islam', Yusuf A Abdulrahman²* and Tharek A Rahman²
}

\begin{abstract}
An improved approach of predicting rain attenuation cumulative distribution (CD) over terrestrial microwave links operating in tropical regions is presented in this article. The proposed method offers a better extrapolation approach for determining the values of rain attenuation at different exceedance probability from the measured attenuation at $0.01 \%$ of the time. The experimental data consist of measured rainfall rates and rain attenuation over six geographically spread DIGI MINI-LINKs operating at $15 \mathrm{GHz}$ in Malaysia. A new set of numerical coefficients was derived for improved rain attenuation CD predictions in the Malaysian tropical climate. In order to test the applicability of the proposed extrapolation method, a validation was performed using rain rate and rain attenuation measurements from five Brazilian and seven Nigerian tropical locations. When tested against measurements, the proposed method seems to provide a significant improvement over the current extrapolation method adopted by ITU-R Recommendations P.530-14, for the prediction of rain attenuation CD over tropical regions.
\end{abstract}

\section{Introduction}

Heavy traffic in the C-band has forced telecommunications service providers to migrate to higher frequency bands, which have enough band-widths to support numerous users. However, rain-induced attenuation is the major issue at frequencies above $10 \mathrm{GHz}$, more especially in tropical regions which experience heavier rainfall intensities [1]. Rain attenuation plays significant role in the design of terrestrial and Earth-satellite radio links especially at frequencies above $10 \mathrm{GHz}$ [2].

The major difficulty faced by engineers working on higher bands is balancing the trade-off between bandwidth availabilities and rain attenuation issues. Even though ITU-R has provided a methodological approach for predicting the rain attenuation on any terrestrial radio link, the model does not perform well in tropical climates because it is based on data collected from temperate regions $[2,3]$. A number of research works have been published to emphasize the inappropriateness of ITU-R method in tropical regions [2-4]. Generally, the required inputs in most attenuation prediction models

\footnotetext{
* Correspondence: abdulrahman.yusuf@yahoo.com

${ }^{2}$ Wireless Communications Center, Faculty of Electrical Engineering, Universiti

Teknologi Malaysia, Malaysia, Skudai, Johor Bahru, Malaysia

Full list of author information is available at the end of the article
}

are the rainfall rate exceeded at $\% p$ of time, the effective propagation path length, and the link's operating frequency [5].

Da Silva Mello et al. [3] have reported that the extrapolation procedure of Equation (4) adopted by the current ITU-R P.530-14 [6] is the major limitation of the prediction method. This is because the same rain attenuation will be predicted for two regions with different rainfall rate regimes but similar values of $A_{0.01}$. In his efforts to correct the inappropriateness, the method of using the full rainfall rate distribution is introduced as input for predicting the rain attenuation cumulative distribution $(\mathrm{CD})$.

In this article, nonlinear multiple regression and moving average techniques have been employed for fitting the measured rain attenuation at different time percentages. Based on the numerical results obtained, a more accurate prediction method has been proposed for extrapolating determining the values of attenuation at different exceedance probability $\% p$ from the measured attenuation at $0.01 \%$ of the time. The measured attenuation data have been tested against the proposed method and ITU-R predictions; and it was found that the proposed method seems to be more suitable than the ITU method for the Malaysian tropical climate. 


\section{Background}

\subsection{Definitions}

Rain attenuation is defined as the product of specific attenuation $(\mathrm{dB} / \mathrm{km})$ and the effective propagation path length $(\mathrm{km})$. The product of path reduction factor and the physical path length of a microwave link is referred to as the effective path length. Attenuation can be obtained from direct measurements or predicted from the knowledge of rain rate. The rain attenuation $A_{\% p}$ exceeded at $\% p$ of time is calculated as follows:

$$
\begin{aligned}
& A \% p=\gamma \% p d_{\text {eff }} \\
& \gamma_{\% p}=k R_{\% p}^{\alpha} \\
& d_{\text {eff }}=d r \% p
\end{aligned}
$$

where $R_{\% p}(\mathrm{~mm} / \mathrm{h})$ is the rain rate exceeded at \%p of the time, $r_{\% p}$ is the path reduction factor at $\% p$ of the time, $d(\mathrm{~km})$ is the link path length. Parameters $k$ and $\alpha$ depend on frequency, rain drop shape, rain temperature, and polarization; and the values of these parameters can be obtained from ITU-R P.838-3 [7].

\subsection{ITU-R rain attenuation prediction method}

According to Recommendation ITU-R P.530-14 [6], the rain attenuation $A_{0.01}$ (in $\mathrm{dB}$ ) at $0.01 \%$ of the time on any terrestrial link is obtained by simply substituting \% $p=0.01$ in Equation (1). This method assumes that an equivalent rain cell of uniform rainfall rate and length $d_{0}$ can model non-uniform rainfall rate along the propagation path. The reduction factor is given by:

$$
r=\frac{1}{1+d / d_{0}}
$$

where

$$
d_{0}=35 e^{-0.015 R_{0.01}}
$$

The attenuation exceeded for other time percentages, $p$, of an average year may be calculated from the value of $A_{0.01}$ by using the following:

$$
A_{\% p}=0.12 A_{0.01} p^{-\left(0.546+0.043 \log _{10}(p)\right)}
$$

The major draw-back of the extrapolation approach of Equation (4) is that it does not perform well in tropical regions, especially at higher rain rates [3].

\section{Methodology and Analyses of experimental data}

One-year rain attenuation data were sampled every second, collected from five operational point-to-point microwave links of DiGi Telecommunications Sdn. Bhd., Malaysia. Each of the microwave systems consists of a microwave MINILINK operating at $15 \mathrm{GHz}$ with data acquisition and processing system. Both transmit and receive antennas are horizontally polarized; and the elevation angle is approximately zero degrees. In order to achieve reliable results, the antennas were covered with radome to ensure that the measured rain attenuation was not contaminated by wet antenna losses during measurement. Moreover, scintillations and other atmospheric absorptions along the propagation path have not been considered in the study. This is because the vapor absorption is significant at $22 \mathrm{GHz}(0.16 \mathrm{~dB} / \mathrm{km})$ and the oxygen absorption at $60 \mathrm{GHz}(15 \mathrm{~dB} / \mathrm{km})$ [5]. The MINILINKs have availability of $99.95 \%$ and their specifications are given in Table 1 . The positioning of the antennas (transmitter and receivers) ensures that the radiation pattern is such that the sidelobes are not pointing to the ground. So, the level of ground contamination (noise) entering the sidelobes is negligible. This implies that there would be negligible interference from any other radiating sources. The dynamic range of the maximum signal strength is about $50 \mathrm{~dB}$ for excess (i.e., rain) attenuation. This is adequately suitable for covering the entire dynamic range of rain attenuation for this investigation, since the highest total path attenuation measured is $49.32 \mathrm{~dB}$ at $0.001 \%$ of the time.

In addition, 1-min rainfall rate data were collected for 4 years at both campuses of Universiti Teknologi Malaysia (UTM), Malaysia (UTM-Skudai and UTM Kuala-Lumpur campuses). The Skudai campus is located at Johor, southern part of Malaysia peninsula close to Singapore with annual average accumulation as high as $4184.3 \mathrm{~mm}$. The average values of the 4-year rainfall rate measurements have been correlated with the 1-year measured attenuation data for these two locations due to seasonal variability of the rainfall pattern. Since rain rate $\mathrm{CD}$ varies from year to year, most especially at higher rain rates, we have assumed that 4-year CD will be fairly stable; and take care of any anomalies that might have been observed during the rain rate data collection. For instance, the average annual value

Table 1 Specifications of the $15 \mathrm{GHz}$ link in Malaysia

\begin{tabular}{lll}
\hline Type of antenna & Front-fed parabolic \\
\hline Frequency band $(\mathrm{GHz})$ & $14.80-15.30$ \\
Polarization & Horizontal & \\
Maximum transmit power $(\mathrm{dBm})$ & +18.0 & \\
BER Received threshold $(\mathrm{dBm})$ & -84.0 & \\
Antenna beam width & $2.3^{0}$ & \\
Dynamic range $(\mathrm{dB})$ & 50.00 & \\
Antenna for both transmit and receive side & Size $(\mathbf{m})$ & Gain (dBi) \\
& 0.6 & 37.0 \\
\hline
\end{tabular}


of the 4-year rainfall rate data will have a lower variance and thus smaller variation.

For the remaining four sites (Alor Star, Penang, Taiping, and Temerloh), the average of 12-year rain-rate data collected from Malaysian Meteorological Station have been used in the study. These rain-rate data have 1-h integration time, so we used Chebil and Rahman's model $[8,9]$ for converting them to the equivalent 1 -min integration time. Again, the average values of the 12year rainfall rate measurements have been correlated with the 1-year measured attenuation data for the four sites due to seasonal variability of the rainfall pattern. Chebil and Rahman's model was based on rainfall data of 1-h integration time collected from over 70 locations in Malaysia, Indonesia, and Singapore. The conversion method has been found to be quite accurate and reliable, within reasonable limit of statistical accuracy, for the Malaysian tropical region and other tropical regions [10]. However, the conversion method is limited to $0.001 \% \leq p \leq 1.0 \%$ of the time when rainfall rate is exceeded. Due to this constraint, the method could not offer accurate results for high rainfall rates when $p \leq$ $0.001 \%$. Nevertheless, our analyses were limited to the time percentages within the validity range of the rain rate conversion method.

The Casella rain gauge is of tipping bucket type and the bucket size is $0.5 \mathrm{~mm}$ of rain. Rain gauge's availability is $100 \%$, and it has operating temperature range of -10 to $50^{\circ} \mathrm{C}$. The gauge is highly reliable with a tipping accuracy of $\pm 1.00 \%$. Note that about 0.5 -mm bucket size is recommended for tropical countries. For instance in Malaysia, $0.01 \%$ rain rate is higher than $120 \mathrm{~mm} / \mathrm{h}$, which occurs 4 tips per minute with very good resolution. The bucket size of $0.2 \mathrm{~mm}$ needs more than 10 tips per minute for higher rain rate and causes error due to mechanical inertia at higher than $100 \mathrm{~mm} / \mathrm{h}$ rain rate. Figures 1 and 2 show the CDs of measured rain attenuation and rainfall rates for each of the six MINILINKs, while the equal probability plots of concurrently measured rainfall rate and rain attenuation are shown in Figure 3.

In the ITU-R P.530-14 model, the rainfall rate exceeded at $0.01 \%$ of the time is used for predicting the corresponding rain attenuation value. The other percentages of time, within the range of 0.001 to $5.0 \%$, are estimated by an extrapolation approach. The ITU-R predicted value of $A_{0.01}(\mathrm{~dB})$ is much smaller compared to the measured data [11]. In this study, a modification is proposed to the extrapolation formula used in the ITU-R method, based on the results presented in Figures 1,2 , and 3 .

More over, possibly more information may be extracted by analyzing the same set of experimental data presented in Figures 1, 2, and 3. For instance, the relationship between the ITU-R predicted-specific rain attenuation, given in Equation (1b), and effective specific rain attenuation, calculated from experimental data, is shown in Figure 4.

The studies conducted on the microwave propagation characteristics of the six DIGI MINILINKs have shown that there exists a linear between measured attenuation $A_{M}(p)$ and logarithmic value of time percentage, $p$ :

$$
A_{M}(p)=11.0833-4.6833 \log (p)
$$

The correlative coefficients between $A_{\text {eff }}(p)$ and $\log (p)$ are almost -1 for the percentage time $p$ within the range 1.0 to $0.001 \%$. By adopting the generalized expression, given below

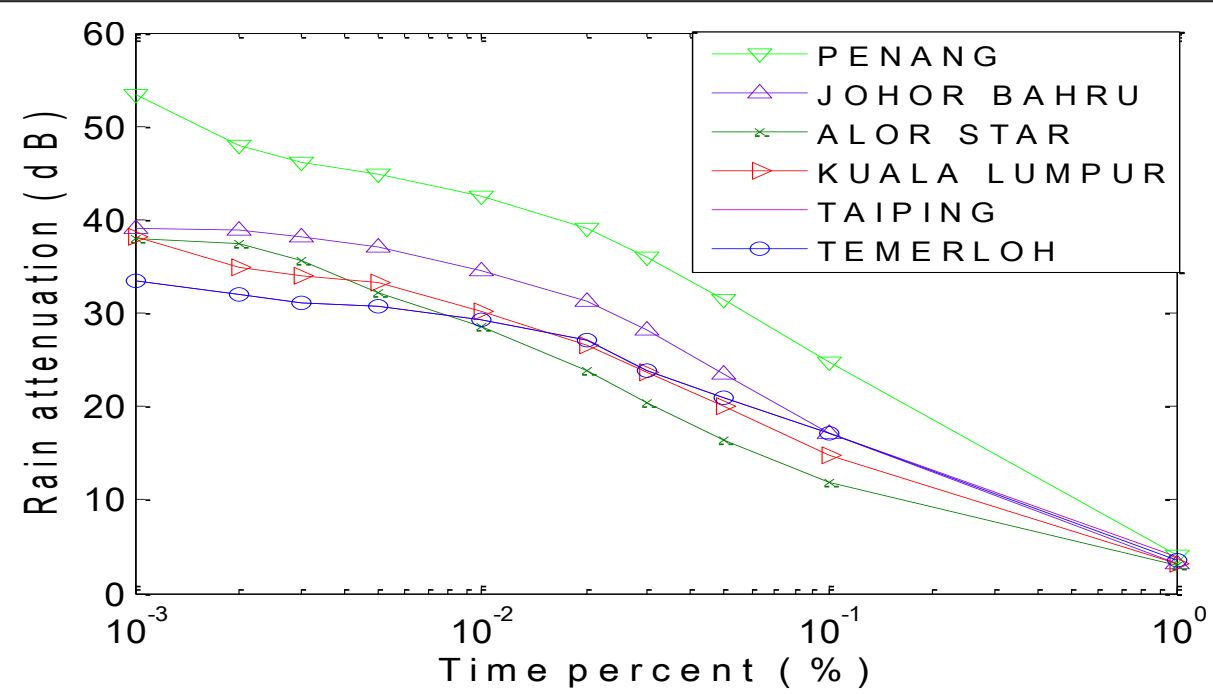

Figure 1 Rain attenuation exceedance at $\% p$ of the time for the six links 


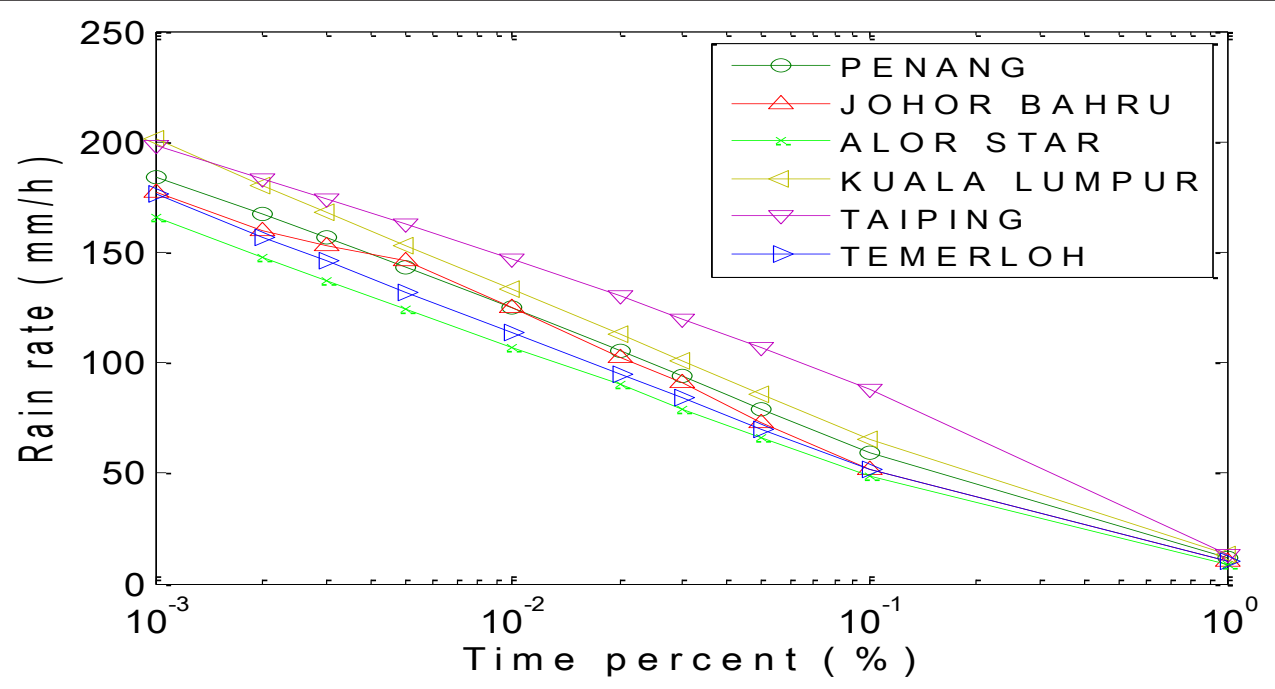

Figure 2 Rainfall rate exceedance at $\% p$ of the time for the six stations.

$$
A_{p} / A_{0.01}=\psi \times p^{-(c+m \log (p))}
$$

where $\psi, c$, and $m$ are regression coefficients whose numerical values were obtained by fitting the measured data shown in Figure 1. The numerical coefficients of the ITU-R method, given in Equation (4), have been adjusted accordingly, based on measurement data in the Malaysian tropical climate, by using nonlinear regression and moving average techniques. Therefore, for predicting $\% p$ of the time at which attenuation $A_{p}$ is exceeded, we propose

$$
A_{p}=0.1689 A_{0.01} p^{\left.-\left(0.5895+0.0996 \log _{10}(p)\right)\right)}
$$

\section{Results and discussions}

The comparison between the measured and predicted rain attenuation over the six terrestrial links in Malaysia at equiprobable exceedance probability $(0.0001 \% \leq p$ $\% \leq 1.0 \%)$ is shown in Figure 5 . As can be clearly seen from this figure, the ITU-R model does not accurately predict the measured attenuation for the six links. The model shows some dramatic behavior, underestimating the measurements at low rain rates, while overestimating the measured rain attenuation at high rain rates. One of the reasons for these inaccuracies may be due to the much smaller ITU-R predicted value for $A_{0.01}$. Another reason maybe that the ITU-R extrapolation

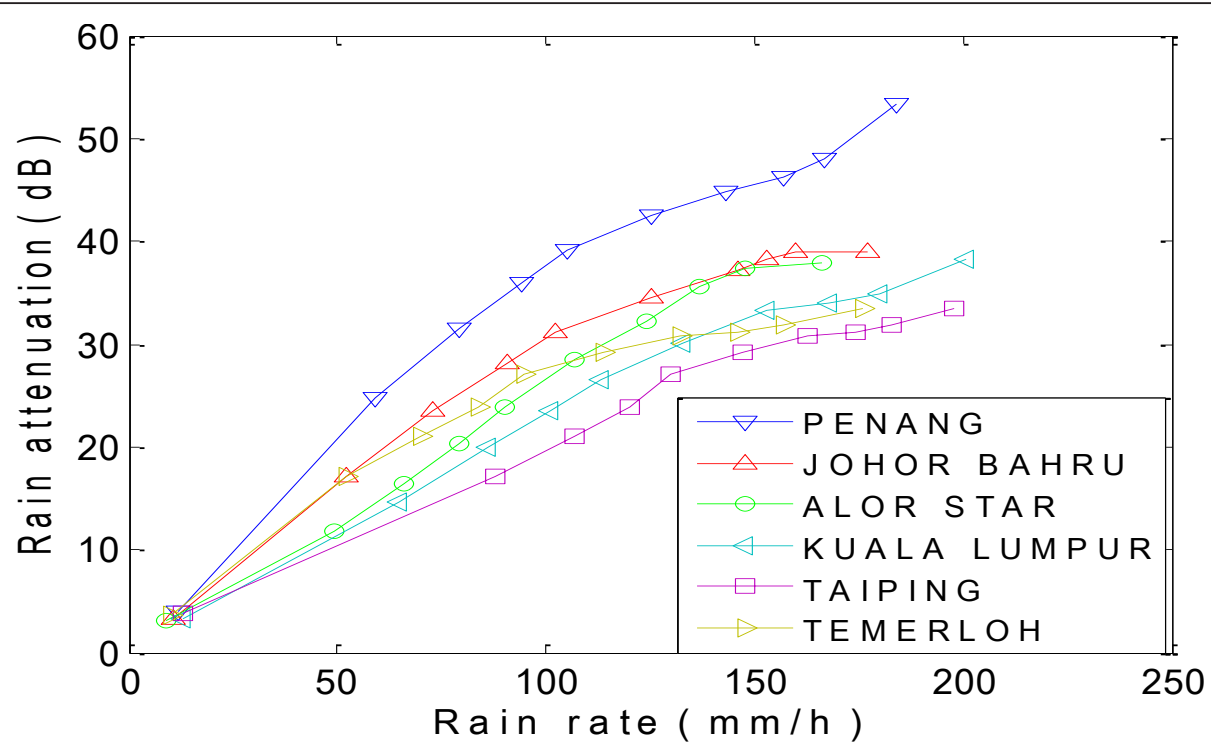

Figure 3 Equal probability plots of rain rate and rain attenuation exceedance at \%p of the time for the six links. 


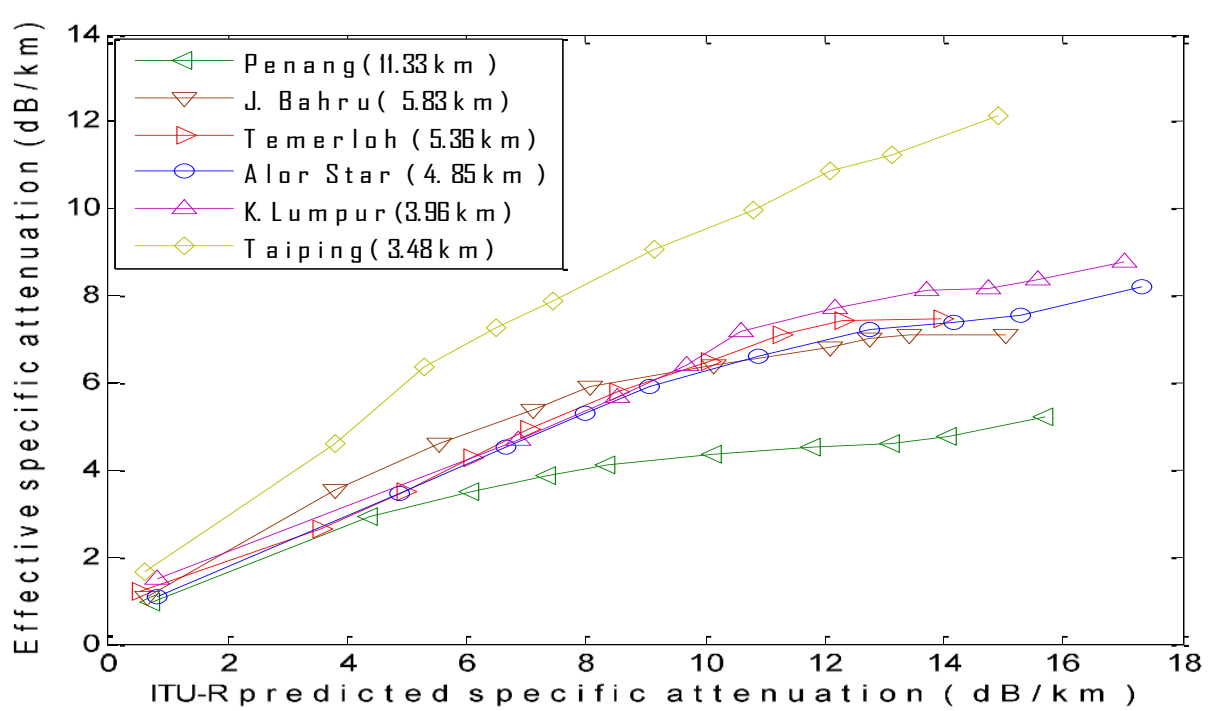

Figure 4 Effective specific rain attenuation against ITU-R predictions.

method predicts that same rain attenuation will be predicted for two regions with different rainfall rate regimes but similar values of $A_{0.01}$.

On the other hand, the modified ITU-R model seems to closely match the measured rain attenuation for all the six links. For instance, the predictions of the proposed modified model are in good agreement with measurements in the range of $1.0 \leq \% p \leq 0.001$ for three links (Alor Star, Kuala Lumpur, and Temerloh). Moreover, the proposed model accurately predicts measurements for the remaining three links (Johor Bahru, Penang, and Taiping) in the range of $1.0 \leq \% p \leq 0.01$. The prediction errors associated with proposed model are generally less than $10 \%$, compared to the ITU-R whose errors are close to $30 \%$, especially at extremely high rain rates.

Moreover, the performance of the proposed method was tested against measured data collected from five Brazilian and seven Nigerian tropical locations. The rainfall rate and rain attenuation data for the Brazilian tropical climate were sourced from [12]. The measured point rainfall rate $\mathrm{CD}$ of Rio de Janeiro, Brazil, is reproduced in Figure 6a, while the characteristics of the five terrestrial links over which rain attenuation was measured are shown in Table 2. Figure 6b shows

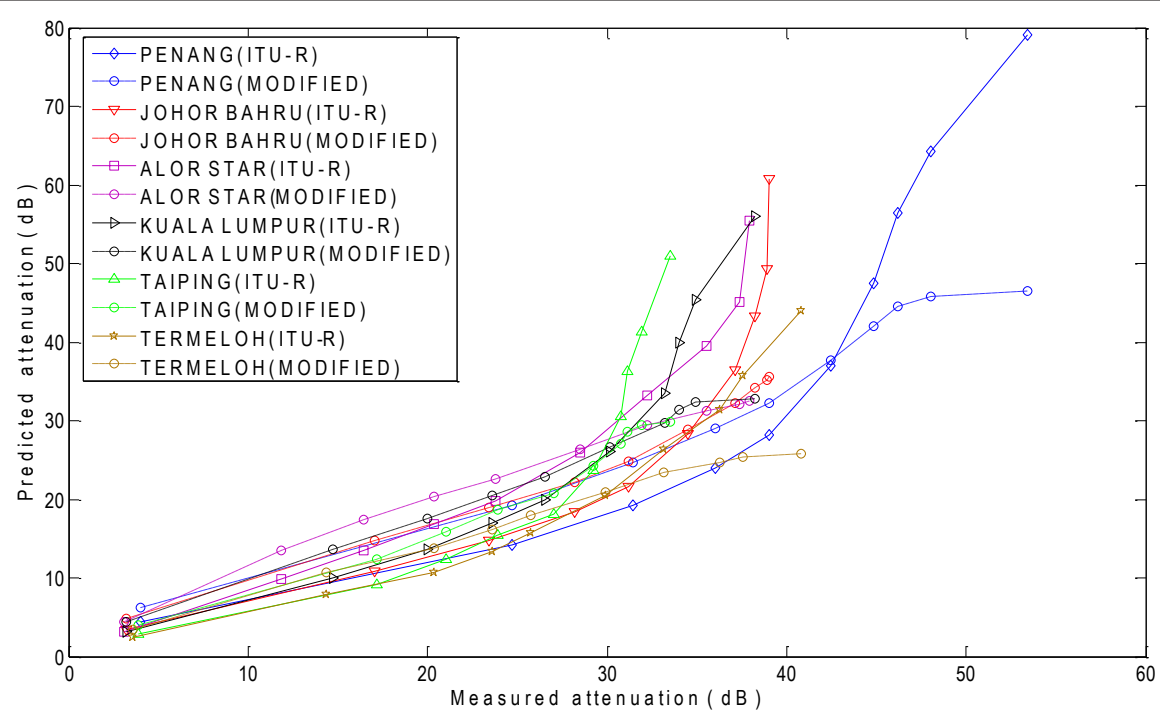

Figure $\mathbf{5}$ Comparison between measured and predicted rain attenuation in Malaysia. 


\section{A}

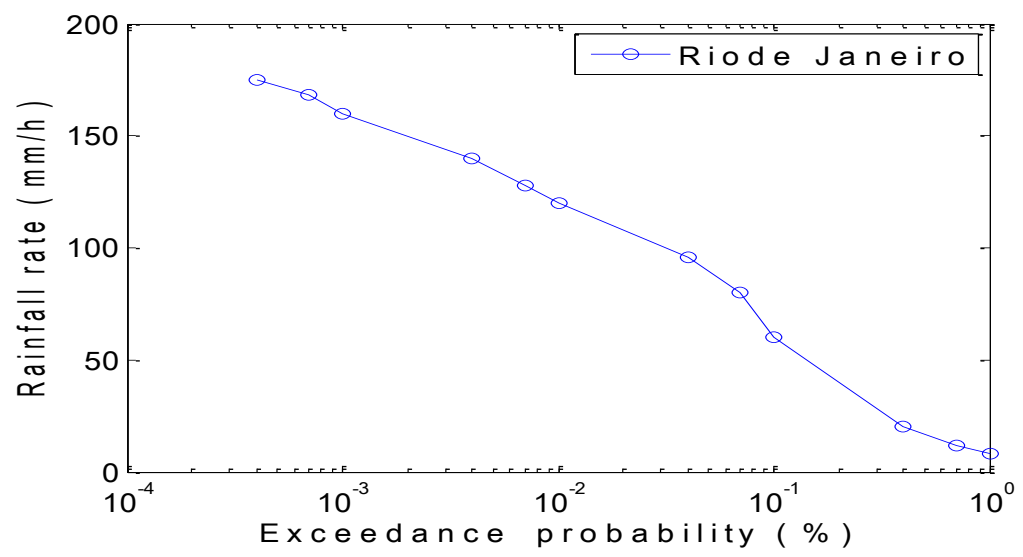

B

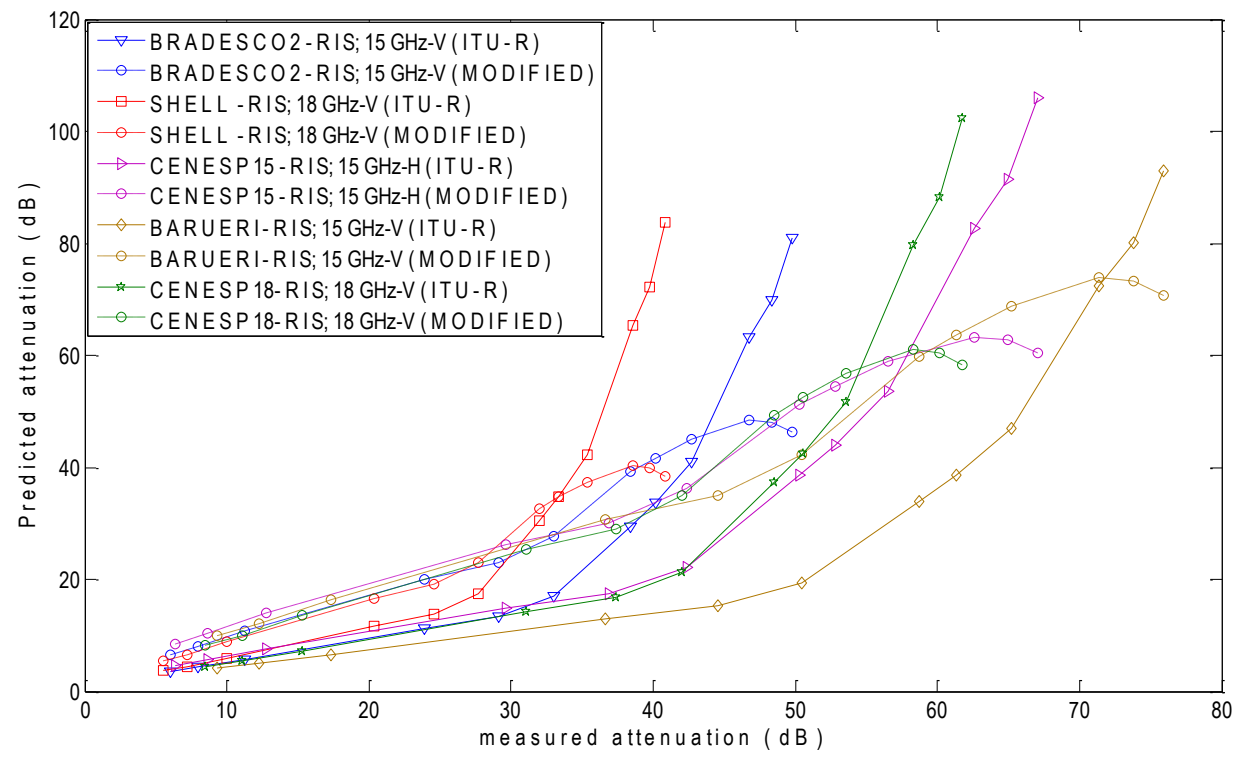

Figure 6 (a) Rainfall rate exceedance at \%p of the time for Rio de Janeiro, Brazil. (b) Comparison between measured and predicted rain attenuation in Brazilian tropical climates.

comparison between the measured and predicted rain attenuation over the terrestrial links at equiprobable exceedance probability $(0.0004 \% \leq p \% \leq 1.0 \%)$.
Due to scarcity of rain attenuation data in Nigeria, the measured point rainfall rates with 1-min integration time, range $0.001 \% \leq \% p \leq 1.0 \%$ [13], were used for 
Table 2 Characteristics of the terrestrial links in Brazil [12]

\begin{tabular}{lllll}
\hline Link & Path length $(\mathbf{k m})$ & Frequency $(\mathbf{G H z})$ & Polarization & Measurement duration (years) \\
\hline Bradesco 2-RIS & 12.8 & 15 & $\mathrm{~V}$ & 2 \\
Shell-RIS & 7.5 & 18 & $\mathrm{~V}$ & 1 \\
Cenesp 15-RIS & 12.8 & 15 & $\mathrm{H}$ & 2 \\
Barueri-RIS & 21.7 & 15 & $\mathrm{~V}$ & 1 \\
Cenesp 18-RIS & 12.8 & 18 & $\mathrm{~V}$ & 1 \\
\hline
\end{tabular}

calculating the terrestrial attenuation over seven geographically spread locations. These locations are Warri, Port Harcourt, Calabar, Lagos, Akure, Ile-Ife, and Ilorin. The first four locations are classified as coastal climates; and a vertically polarized link operating at $18 \mathrm{GHz}$, with a path length $7.5 \mathrm{~km}$, is assumed for each of the locations. The remaining three locations are classified as rain forests; and a horizontally polarized link operating at $15 \mathrm{GHz}$, with a path length $12.8 \mathrm{~km}$, is assumed for each of the locations. Figure 7 shows comparison between the measured and predicted attenuations over the terrestrial links at equiprobable exceedance probability $(0.001 \% \leq \% p \leq 1.0 \%)$.

Figure 8 shows the scatter plots of predicted attenuation values against the measurements available from Malaysia, Brazil, and Nigeria.

As shown in Figures 6b, 7, and 8, the ITU-R method does not match with measurements for all the exceedance probability at which rain rate is exceeded. The method largely underestimates the measured values at low rain rates, while overestimating them at extremely high rain rates. On the other hand, the proposed method seems to match the measured values more accurately, with up to $80 \%$ reduction in relative RMS errors compared to ITU-R method.
The relative error variable used to assess the proposed model performance is given as

$$
E=\frac{A \% p, \text { predicted }-A \%, p \text { measured }}{A_{\%, p \text { measured }}} 100 \% ; \quad 0.001<\% p<1 \%
$$

The measured data were tested against the ITU-R and proposed methods, as shown in Table 3, using the test variable recommended by the ITU-R P. 311-13 [14]. The new set of coefficients given in Equation (7) resulted in an improvement in terms of the RMS of the relative error variable compared to the RMS obtained with the original ITU-R parameters in Equation (4).

\section{Conclusions}

This article has presented the results on rainfall rate, and rain attenuation CDs on six microwave links operating at $15 \mathrm{GHz}$ in tropical Malaysia. The relationship between effective specific attenuation and ITU-R predicted one is investigated. The experimental results have clearly shown that the extrapolation approach adopted by the current ITU-R method seems to be unsuitable for predicting rain attenuation $\mathrm{CD}$ from the knowledge of measured rain attenuation $A_{0.01}$ in Malaysia and similar tropical climates. A new set of numerical coefficients

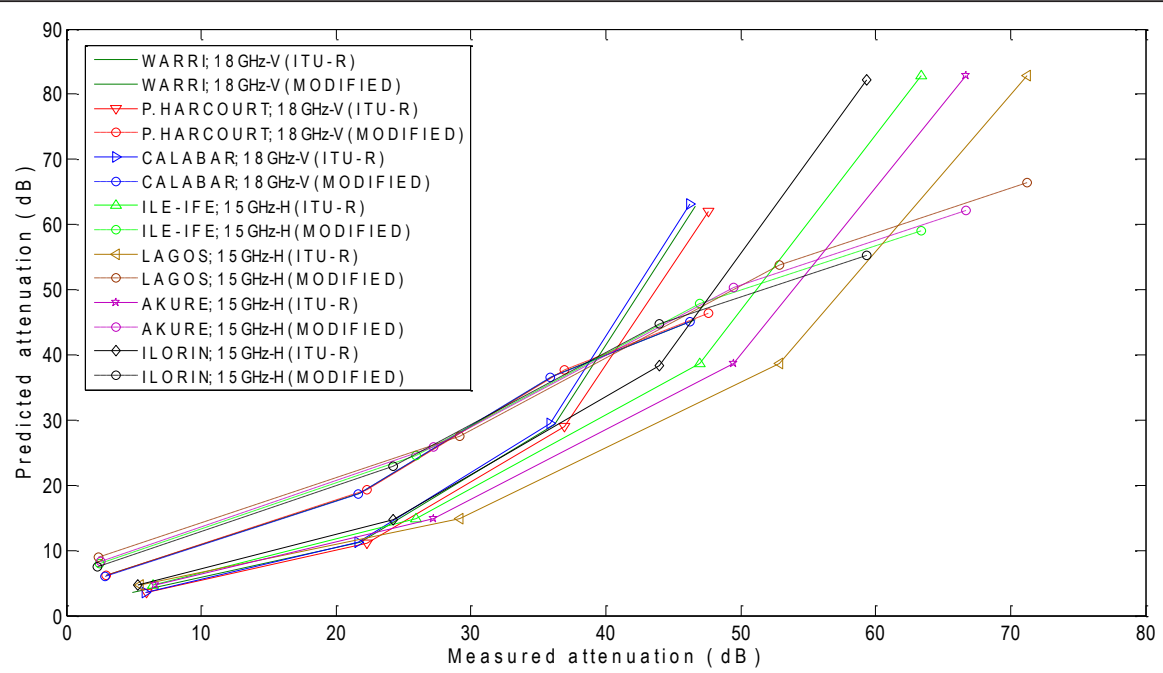

Figure 7 Comparison between measured and predicted rain attenuation in Nigerian coastal and rain forest climates. 


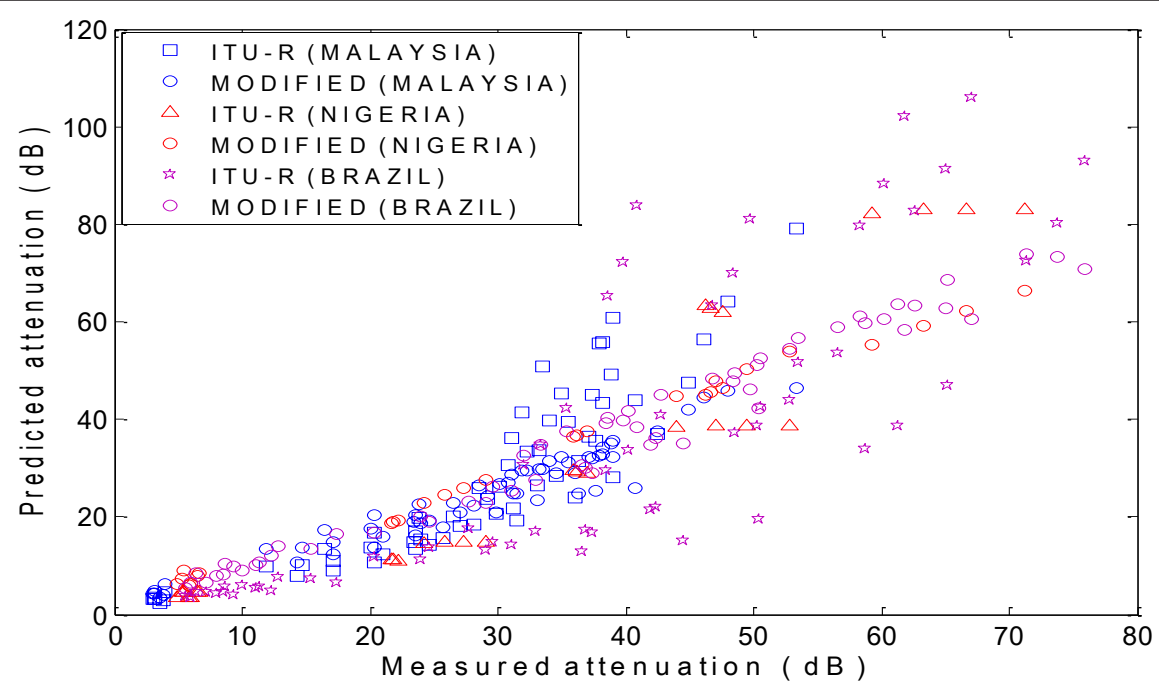

Figure 8 Scatter plot of measured and predicted attenuation values, for Malaysia, Brazil, and Nigeria.

Table 3 Percentage errors comparison

\begin{tabular}{lllllll}
\hline $\boldsymbol{p ( \% )}$ & Mean error & \multicolumn{3}{l}{ Standard deviation } & \multicolumn{2}{l}{ RMS } \\
\cline { 2 - 7 } & Modified & ITU-R & Modified & ITU-R & Modified & ITU-R \\
\hline 0.1 & 0.0054 & -0.0505 & 0.0357 & 0.2103 & 0.0353 & 0.2162 \\
0.05 & -0.0005 & -0.0482 & 0.0361 & 0.2602 & 0.0361 & 0.2647 \\
0.03 & -0.0033 & -0.0408 & 0.0359 & 0.2081 & 0.0358 & 0.2121 \\
0.02 & -0.0064 & -0.0418 & 0.0355 & 0.2591 & 0.0350 & 0.2625 \\
0.01 & -0.0047 & -0.0191 & 0.0358 & 0.2050 & 0.0355 & 0.2059 \\
0.005 & -0.0043 & -0.0133 & 0.0358 & 0.2561 & 0.0356 & 0.2564 \\
0.003 & -0.0049 & 0.0007 & 0.0358 & 0.2049 & 0.0354 & 0.2057 \\
0.002 & -0.0039 & 0.0152 & 0.0359 & 0.2562 & 0.0357 & 0.2566 \\
0.001 & 0.0157 & 0.0304 & 0.0325 & 0.2091 & 0.0284 & 0.2140 \\
\hline
\end{tabular}

Appendix Locations of the stations used in this investigation $[9,10,12]$

\begin{tabular}{|c|c|c|c|c|}
\hline Location & Country & Longitude $\left({ }^{\circ} \mathrm{E}\right)$ & Latitude $\left({ }^{\circ} \mathrm{N}\right)$ & Annual mean accumulation $(\mathrm{mm})$ \\
\hline Penang & Malaysia & 100.29 & 5.27 & 2470.64 \\
\hline Johor Bahru & & 103.43 & 1.30 & 2357.38 \\
\hline Alor Star & & 100.25 & 6.15 & 1894.23 \\
\hline Kuala Lumpur & & 101.36 & 3.04 & 2419.65 \\
\hline Temerloh & & 102.25 & 3.26 & 1702.67 \\
\hline Taiping & & 100.42 & 4.51 & 4048.99 \\
\hline Warri & Nigeria & 5.44 & 5.29 & 2617.5 \\
\hline Port Harcourt & & 7.00 & 4.20 & 2803.1 \\
\hline Calabar & & 8.17 & 4.58 & 2864.9 \\
\hline Lagos & & 3.20 & 7.50 & 1425.2 \\
\hline lle-Ife & & 5.00 & 6.30 & 1262.3 \\
\hline Akure & & 5.18 & 7.17 & 1485.6 \\
\hline Ilorin & & 4.50 & 8.50 & 1232.8 \\
\hline \multirow[t]{2}{*}{ Rio de Janeiro } & Brazil & Longitude $\left({ }^{\circ} \mathrm{W}\right)$ & Latitude ( $\left.{ }^{\circ} \mathrm{S}\right)$ & Annual mean accumulation $(\mathrm{mm})$ \\
\hline & & 46.63 & 23.55 & 1500 \\
\hline
\end{tabular}


was derived for improved rain attenuation $\mathrm{CD}$ predictions in tropical Malaysia.

The applicability of the proposed method was validated using rain measurements from 12 tropical locations. When tested against measurements, the proposed method seems to provide a significant improvement over the current extrapolation method adopted by ITUR Recommendations P.530-14, for the prediction of rain attenuation $\mathrm{CD}$ over tropical regions. The test results presented in Table 3 have also shown that the proposed approach seems to provide a better and more reliable alternative to the ITU-R method in tropical Malaysia, and probably other tropical climates, regardless of link's operating frequencies and polarizations. The new set of parameters resulted in an improvement in terms of the RMS of the relative error variable compared to the RMS obtained with the original ITU-R parameters.

\section{Author details}

${ }^{1}$ Electrical \& Computer Engineering Department, Faculty of Engineering, Islamic International University of Malaysia, Gombak Campus, Selangor, Malaysia ${ }^{2}$ Wireless Communications Center, Faculty of Electrical Engineering, Universiti Teknologi Malaysia, Malaysia, Skudai, Johor Bahru, Malaysia

\section{Competing interests}

The authors declare that they have no competing interests.

Received: 13 February 2012 Accepted: 7 June 2012

Published: 7 June 2012

\section{References}

1. F Moupfouma, Electromagnetic waves attenuation due to rain: a prediction model for terrestrial or L.O.S SHF and EHF radio communication. J Infrared Milli Terahz Waves. 30, 622-632 (2009). doi:10.1007/s10762-009-9481-y

2. GO Ajayi, Some aspects of tropical rainfall and their effect on microwave propagation. Int J Satell Commun. 8(3), 163-172 (1990). doi:10.1002/ sat.4600080308

3. LAR Da Silva Mello, MS Pontes, RM De Souza, NA Perez Garcia, Prediction of rain attenuation in terrestrial links using full rainfall rate distribution. Electron Lett. 43(25), 1442-1443 (2007). doi:10.1049/el:20072410

4. F Moupfouma, L Martin, Modeling of the rainfall rate cumulative distribution for the design of satellite and terrestrial communication systems. Int J Satell Commun. 13(2), 105-115 (1995). doi:10.1002/ sat.4600130203

5. JWF Goddard, Propagation in Rain and Cloud: Spatial Temporal Structure of Rain. Propagation of Radio Waves, 2nd edn. (The Institution of Electrical Engineers, IEE, UK, 2003)

6. ITU-R Recommendation P.530-14, Propagation data and prediction methods required for the design of terrestrial line-of-sight systems. International Telecommunication Union (February 2012)

7. ITU-R Recommendation P.838-3, Specific attenuation model for rain for use in prediction methods. International Telecommunication Union (March 2005)

8. J Chebil, TA Rahman, Rain rate statistical conversion for the prediction of rain attenuation in Malaysia. Electron Lett. 35, 1019-1021 (1999). doi:10.1049/el:19990685

9. AY Abdulrahman, TA Rahman, SK Abdulrahim, MR Islam, MKA Abdulrahman, Rain Attenuation Predictions on Terrestrial Radio Links: Differential Equations Approach. Transactions on Emerging Telecommunications Technologies (TETT). 23, 293-301 (2012)

10. JS Ojo, MO Ajewole, SK Sarkar, Rain rate and rain attenuation prediction for satellite communication in $\mathrm{Ku}$ and $\mathrm{Ka}$ bands over Nigeria. Prog Electromagnet Res B. 5, 207-223 (2008)
11. JX Yeo, YH Lee, JT Ong, Modified ITU-R slant path rain attenuation model for the tropical region, in 7th International Conference on Information, Communications and Signal Processing, ICICS, pp. Macau 1-4 (December 2009)

12. MS Pontes, LAR Da Silva Mello, RSL Souza, ECB Miranda, Review of rain attenuation studies in tropical and equatorial regions in Brazil. in Proceeding of the 5th International Conference on Information, Communications and Signal Processing (ICICSP '05) IEEE Xplore, Bangkok 1097-1101 (2005)

13. IS Ojo, MO Ajewole, LD Emiliani, One-minute rain rate contour maps for microwave communication systems planning in a tropical country: Nigeria. IEEE Antenna Propag Mag. 51(5), 82-89 (2009)

14. ITU-R Recommendation P.311-13, Acquisition, presentation and analysis of data in studies of tropospheric propagation. International Telecommunication Union (October 2009)

doi:10.1186/1687-1499-2012-189

Cite this article as: Islam et al:: An improved ITU-R rain attenuation prediction model over terrestrial microwave links in tropical region. EURASIP Journal on Wireless Communications and Networking 2012 2012:189.

\section{Submit your manuscript to a SpringerOpen ${ }^{\circ}$ journal and benefit from:}

- Convenient online submission

- Rigorous peer review

- Immediate publication on acceptance

- Open access: articles freely available online

- High visibility within the field

- Retaining the copyright to your article

Submit your next manuscript at $>$ springeropen.com 